\title{
Association between overtime work hours and preventive dental visits among Japanese workers
}

\author{
Yoshikazu Harada ${ }^{1,2+}$ (D), Tomohisa Nagata ${ }^{3 *}$ (D) Masako Nagata ${ }^{3}$, Arisa Harada ${ }^{4}$, Ryoichi Oya ${ }^{1}$ and Koji Mori ${ }^{3}$ (D)
}

\begin{abstract}
Background: This study aimed to examine the association between overtime work and the frequency of preventive dental visits among workers in Japan.

Methods: A self-administered questionnaire was completed by 14,847 daytime-workers. We used a logistic regression model stratified by sex and age and adjusted for marital status, occupation, education, and oral status to investigate the association between overtime work hours and the frequency of preventive dental visits.

Results: In total 1037 men (9.3\%) and 511 women (13.9\%) attended quarterly preventive dental visits, and 2672 men (23.9\%) and 1165 women (31.8\%) attended annual preventive dental visits. Overtime work was statistically significantly associated with quarterly preventive dental visits among men aged 50-59 years, with adjusted odds ratios (aOR) and 95\% confidence intervals (Cl) of $0.73(0.56-0.95), 0.75(0.54-1.04)$, and $0.55(0.34-0.90)$ for $<20,20-39$, and $\geq 40 \mathrm{~h}$ overtime/month, respectively. No such trends were observed for men aged $<50$ years and women of all ages. Overtime work of $<20,20-40$, and $\geq 40 \mathrm{~h}$ overtime/month was statistically significantly associated with annual preventive dental visits among men aged 40-49years (aOR [95\%Cl]: 0.76 [0.61-0.95], 0.84 [0.65-1.09], and 0.72 [0.511.00], respectively) and 50-59 years (aOR [95\%Cl]: 0.75 [0.61-0.91], 0.76 [0.59-0.97], and 0.63 [0.45-0.88], respectively). No such trends were observed in men $<40$ years and women of all ages.
\end{abstract}

Conclusions: Our study revealed associations between overtime and preventive dental visits among male workers aged in their 40s and 50s.

Keywords: Overtime work, Preventive dental visits, Oral health, Workplace

\section{Background}

Periodontitis and caries are the most common causes of permanent tooth loss [1-4]. Permanent tooth loss is associated with a reduction in intraoral function, and an increased risk for depression and cognitive decline $[5,6]$. In addition, periodontitis has been identified as a risk

\footnotetext{
* Correspondence: tomohisa@med.uoeh-u.ac.jp

${ }^{\dagger}$ Yoshikazu Harada and Tomohisa Nagata contributed equally to this work. ${ }^{3}$ Department of Occupational Health Practice and Management, Institute of Industrial Ecological Sciences, University of Occupational and Environmental Health, 1-1 Iseigaoka, Yahatanishi-ku, Kitakyushu 807-8555, Japan

Full list of author information is available at the end of the article
}

factor for systemic diseases such as diabetes and coronary heart disease [7-9].

Previous studies reported that overtime work increased the risk for developing diseases such as coronary heart disease, stroke, diabetes, and mental health disorders [9-13]. Recently, overtime work has been identified as a risk factor for increased morbidity of dental diseases, such as caries and periodontitis $[4,9]$. A survey of medical doctor trainees showed $71.4 \%$ had delayed or missed preventive dental examinations, with the main reason being lack of time because of work commitments [14].

(c) The Author(s). 2021 Open Access This article is licensed under a Creative Commons Attribution 4.0 International License, which permits use, sharing, adaptation, distribution and reproduction in any medium or format, as long as you give appropriate credit to the original author(s) and the source, provide a link to the Creative Commons licence, and indicate if changes were made. The images or other third party material in this article are included in the article's Creative Commons licence, unless indicated otherwise in a credit line to the material. If material is not included in the article's Creative Commons licence and your intended use is not permitted by statutory regulation or exceeds the permitted use, you will need to obtain permission directly from the copyright holder. To view a copy of this licence, visit http://creativecommons.org/licenses/by/4.0/ The Creative Commons Public Domain Dedication waiver (http://creativecommons.org/publicdomain/zero/1.0/) applies to the data made available in this article, unless otherwise stated in a credit line to the data. 
Preventive dental visits to maintain good oral condition (e.g., check-ups, professional teeth cleaning, and oral hygiene advice) has beneficial effects for oral health, and poor oral hygiene is a major risk factor for periodontitis and caries. Professional teeth cleaning combined with oral hygiene advice results in a reduction in plaque and gingival bleeding [15]. In addition, dental visits reduce the incidence of periodontitis [16]. Women and older individuals are more likely to attend preventive dental visits [17]. Highly educated people also have more frequent dental visits for check-ups than poorly educated people [18]. Research suggests that overtime workers have fewer opportunities to visit hospital for general medical treatment than those that do not work overtime [19]. However, if opportunities for preventive dental visits decrease, the morbidity associated with these diseases may increase. In addition, an increase in periodontitis may influence the increase of other diseases such as coronary heart disease.

A previous cross-sectional study examined the association between working hours and use of preventive health services [20]. Individuals working long hours (> 60 per week) were significantly less likely to attend dental check-ups and cancer screening (e.g., mammograms) than those working shorter hours. Factors contributing to these results were time barriers to making appointments for screening visits and time barriers to keeping any appointments made. Another study revealed that $71 \%$ of participants reported delaying or skipping preventive dental examinations because of lack of time to schedule and attend appointments [14]. However, it is difficult to apply those results more generally because the sample size in that study was small and all participants were medical doctors.

The impact of visits to a dental clinic for preventive purposes (rather than for dental examinations) has not been examined. Therefore, we conducted the present study to examine the association between overtime work and preventive dental visits among men and women in different age groups. Preventive dental visits refer to visits to a dental clinic for preventive purposes, rather than for a set dental check-up.

\section{Methods}

This cross-sectional study included participants from six companies in Japan (five manufacturing companies and one information and communications company). Participating companies did not conduct dental examinations. A self-administered questionnaire was disseminated to 32,026 workers across the six companies between July and October 2017. Participants received an explanation about the study and were informed that completion of the self-administered questionnaire was voluntary. The number of participants (response rate) from each of the six companies was 5728 (81.4\%), 4083 (71.0\%), 3943
(43.3\%), 2302 (72.7\%), 709 (11.7\%), and 418 (46.5\%). This gave a total of 17,183 participants (overall response rate: $53.7 \%)$.

The questionnaire collected information on personal characteristics, such as educational background, working conditions (working pattern [daytime, shift work, night shift and semi-night shift], mean overtime hours per month), preventive dental visits, and oral status (see Additional file 1). For the purpose of this study, 1674 shift workers (1580 shift work, 33 night shift, 28 seminight shift, and 33 with missing data) were excluded to eliminate the effect of shift work on the frequency of preventive dental visits. Workers aged 60 years and over $(n=662)$ were also excluded from the study population because working conditions in Japan change significantly for those over age 60 years. Therefore, 14,847 workers who provided valid responses were included in the present analysis.

This study used a web-based survey. The study design was explained to all employees and employers via email, the company's intranet homepage, or the company's occupational health and safety committee. Employees could freely choose whether to participate in this study. Employees' responses to the questionnaire were not disclosed to their employers. The research protocol was approved by the Ethics Committee of Medical Research, University of Occupational and Environmental Health, Japan (H26-026).

\section{Explanatory variable: mean overtime work hours per month}

The item assessing participants' overtime was: "What was your mean number of overtime work hours per month in the last 6 months? Please choose the most applicable option (include working hours on holidays; do not include commuting time)." There were 12 response options: $0,<10,10-19,20-29,30-39,40-49,50-59$, 60-69, 70-79, 80-89, 90-99, and $\geq 100 \mathrm{~h}$. Mean overtime hours were grouped into four categories: $0,<20$, 20-39, and $\geq 40 \mathrm{~h}$.

\section{Outcome: frequency of preventive dental visits}

A Likert scale question with five levels was used to assess the frequency of preventive dental visits. Participants were asked "Are you currently visiting a dental clinic for prevention?" Response options were: "more than once every 3 months," "once every 6 months," "once a year," "sometimes," and "never." A previous study reported that dental visits at an interval of 3 months $[15,21]$ or more than once per year [16] prevent periodontitis. We set two outcomes (binary variables). The first outcome was "more than once every 3 months" (yes or no), and this was classified as "quarterly preventive dental visits." The second outcome was annual visits 
for prevention (yes or no), which included "more than once every 3 months," "once every 6 months," and "once a year." This outcome was categorized as "annual preventive dental visits."

\section{Covariates}

Age was considered a continuous variable and categorized as $\leq 29,30-39,40-49$, and 50-59 years. The categories for occupation (clerk, sales, research and development, engineer, production line and engineer, others) were taken from the human resource data of the participating companies. Marital status was classified into four groups: married, unmarried (single), unmarried (living with family and relatives), and divorced/bereaved. Responses were categorized as married, single/unmarried, and divorced/bereaved. Educational background and oral health status are thought to affect the dental visit behavior [18]. Educational background was categorized as "junior high school or high school," "junior college, technical school, or high professional school," "college," or "postgraduate." To understand oral health status, we asked participants: "During the past month, have you had any dental problems (such as toothache)?" (yes or no). We defined this variable as "dental problems."

\section{Statistical analysis}

We calculated the proportions of participants who made quarterly preventive dental visits and annual preventive dental visits for each subgroup (age, occupation, marital status, education, dental problems, and overtime work hours per month) stratified by sex. Chi-square tests were performed to evaluate associations in each category.

Logistic regression analysis was used to examine the association between overtime work hours and preventive dental visits, stratified by sex and age because the frequency of regular dental visits is high for women and older age groups in Japan [17]. "Quarterly preventive dental visits" and "annual preventive dental visits" were set as the outcome variables. "Overtime work hours" was set as an exposure variable. Adjusted odds ratios (aOR) and $95 \%$ confidence intervals $(\mathrm{CI})$ were calculated, with adjustment for factors that may be associated with preventive dental visits (occupation, marital status, educational background, and dental problems) [18]. Workers with dental problems may be more likely to attend preventive dental visits than workers without dental problems because they may take preventive measures when visiting a dentist for treatment. Therefore, we performed an additional sensitivity analysis involving workers without dental problems. Statistical significance was set at $p<0.05$. All analyses were conducted using IBM SPSS 25.0 software (SPSS Inc., Chicago, Illinois) and Stata 16.0 software (StataCorp. Texas, USA).

\section{Results}

Overall, 11,179 men (75.3\%) and 3668 women (24.7\%) responded to the questionnaire (Table 1 ). The age distribution ( $\leq 29,30-39,40-49$, and $50-59$ years) was 8,21 , 37 , and $34 \%$ in men and $20,25,35$, and $20 \%$ in women, respectively. The majority of men were married (79\%), whereas the number of single and married respondents was almost the same for women. Overall 6\% of respondents (both men and women) had dental problems.

Table 2 shows the association between preventive dental visits and demographic characteristics excluding those with missing data $(n=2)$ for outcomes. In total, 1037 men (9.3\%) and 511 women (13.9\%) attended quarterly preventive dental visits, and 2672 men (23.9\%) and 1165 women $(31.8 \%)$ attended annual preventive dental visits. In any analysis of annual and quarterly preventive dental visits, the proportion of respondents attending preventive dental visits tended to increase as age increased for both men and women. In addition, the proportion of respondents attending preventive dental visits decreased as working hours increased. Men and women with dental problems tended to proactively visit a dental clinic more often.

Table 3 shows the results of the association between preventive dental visits and overtime work hours, stratified by sex and age. Overtime work had a statistically significant association with quarterly preventive dental visits among men aged 50-59 years, with aORs (95\%CI) of 0.73 (0.56-0.95, $p=0.019), 0.75(0.54-1.04, p=0.085)$, and $0.55(0.34-0.90, p=0.017)$ for $<20,20-40$, and $\geq 40 \mathrm{~h}$ overtime/month, respectively (reference: men of the same age with no overtime). No such trends were observed in men aged < 50 years and women of all ages. Overtime work had a statistically significant association with annual preventive dental visits among men aged $40-49$ years, with aORs $(95 \% \mathrm{CI})$ of $0.76(0.61-0.95, \mathrm{p}=$ $0.017)$, 0.84 (0.65-1.09, $p=0.194)$, and $0.72(0.51-1.00$, $p<0.05)$ for $<20,20-40$, and $\geq 40 \mathrm{~h}$ overtime/month, respectively (reference: men of the same age with no overtime). Similar results were observed for men aged 5059 years, with aORs $(95 \% \mathrm{CI})$ of $0.75(0.61-0.91, p=$ $0.004), 0.76(0.59-0.97, p=0.028)$, and $0.63(0.45-0.88$, $p=0.007)$ for $<20,20-40$, and $\geq 40$ h overtime/month, respectively (reference: men of the same age with no overtime). No such trends were observed in men aged $<40$ years and women of all ages.

Table 4 shows the results of the sensitivity analysis among workers without dental problems. The results were the same in both the sex and age categories.

\section{Discussion}

Our study revealed associations between overtime and preventive dental visits among male workers aged in their 40s and 50s. This association was more 
Table 1 Demographic characteristics of 14,847 respondents from six companies

\begin{tabular}{|c|c|c|c|c|}
\hline & \multicolumn{2}{|l|}{ Men } & \multicolumn{2}{|c|}{ Women } \\
\hline & $\mathbf{N}$ & $\%$ & $\mathbf{N}$ & $\%$ \\
\hline Total & 11,179 & 75.3 & 3668 & 24.7 \\
\hline \multicolumn{5}{|l|}{ Age, years } \\
\hline$\leqq 29$ & 893 & 8.0 & 716 & 19.5 \\
\hline $30-39$ & 2338 & 20.9 & 932 & 25.4 \\
\hline $40-49$ & 4177 & 37.4 & 1298 & 35.4 \\
\hline $50-59$ & 3771 & 33.7 & 722 & 19.7 \\
\hline \multicolumn{5}{|l|}{ Occupation } \\
\hline clerk & 3388 & 30.3 & 1385 & 37.8 \\
\hline sales & 4291 & 38.4 & 861 & 23.5 \\
\hline research and development & 1428 & 12.8 & 820 & 22.4 \\
\hline engineer & 276 & 2.5 & 86 & 2.3 \\
\hline production line and engineer & 1567 & 14.0 & 380 & 10.4 \\
\hline others & 228 & 2.0 & 135 & 3.7 \\
\hline missing & 1 & 0.0 & 1 & 0.0 \\
\hline \multicolumn{5}{|l|}{ Marriage status } \\
\hline Married & 8794 & 78.7 & 1779 & 48.5 \\
\hline Single & 2085 & 18.7 & 1680 & 45.8 \\
\hline Divorce or bereavement & 261 & 2.3 & 179 & 4.9 \\
\hline Missing & 39 & 0.3 & 30 & 0.8 \\
\hline \multicolumn{5}{|l|}{ Education (graduate status) } \\
\hline Junior high school or high school & 1638 & 14.7 & 913 & 24.9 \\
\hline Junior college or technical school or high professional school & 464 & 4.2 & 695 & 18.9 \\
\hline College & 6093 & 54.5 & 1354 & 36.9 \\
\hline More than graduate school & 2945 & 26.3 & 680 & 18.5 \\
\hline Missing & 39 & 0.3 & 26 & 0.7 \\
\hline \multicolumn{5}{|l|}{ Dental problems } \\
\hline No & 10,264 & 91.8 & 3410 & 93.0 \\
\hline Yes & 615 & 5.5 & 221 & 6.0 \\
\hline Missing & 300 & 2.7 & 37 & 1.0 \\
\hline \multicolumn{5}{|c|}{ Overtime work hours } \\
\hline None & 1301 & 11.6 & 643 & 17.5 \\
\hline$<20$ & 6266 & 56.1 & 2302 & 62.8 \\
\hline $20 \leqq,<40$ & 2765 & 24.7 & 596 & 16.2 \\
\hline $40 \leqq$ & 813 & 7.3 & 105 & 2.9 \\
\hline Missing & 34 & 0.3 & 22 & 0.6 \\
\hline
\end{tabular}

pronounced in people working longer hours; however, even a small amount of overtime work $(<20 \mathrm{~h}$ a month) statistically significantly reduced preventive dental visits.

Some occupational factors, such as overtime work [9] and shift work [22], have been reported to increase the morbidity of dental diseases (e.g., periodontal disease); however, the direct cause has not yet been established. Preventive dental visits reduce the risk for caries and periodontal disease and have an important role in oral hygiene. The results of this study suggested that overtime work may increase dental disease morbidity in workers because of a decrease in preventive dental visits.

Overtime work had significant associations with nonattendance of preventive dental visits among male workers aged in their 40s and 50s. However, men in their 20 s and 30 s did not show any statistically 
Table 2 Distribution of preventive dental visits according to sex among 14,845 workers, excluding missing data for preventive dental visits $(n=2)$

\begin{tabular}{|c|c|c|c|c|c|c|c|c|c|c|c|c|c|}
\hline & & \multicolumn{6}{|c|}{ Quarterly preventive dental visit } & \multicolumn{6}{|c|}{ Annual preventive dental visit } \\
\hline & & \multicolumn{3}{|c|}{ Men } & \multicolumn{3}{|c|}{ Women } & \multicolumn{3}{|l|}{ Men } & \multicolumn{3}{|c|}{ Women } \\
\hline & & $\mathrm{N}$ & $\%$ & $\overline{p \text { value }}$ & $\mathrm{N}$ & $\%$ & $\overline{p \text { value }}$ & $\bar{N}$ & $\%$ & $\overline{p \text { value }}$ & $\bar{N}$ & $\%$ & $\overline{p \text { value }}$ \\
\hline \multirow[t]{4}{*}{ Age, years } & $\leq 29$ & 40 & 4.5 & $<0.001$ & 67 & 9.4 & $<0.001$ & 149 & 16.7 & $<0.001$ & 157 & 21.9 & $<0.001$ \\
\hline & $30-39$ & 178 & 7.6 & & 142 & 15.2 & & 545 & 23.3 & & 345 & 37.0 & \\
\hline & $40-49$ & 382 & 9.1 & & 154 & 11.9 & & 969 & 23.2 & & 410 & 31.6 & \\
\hline & $50-59$ & 437 & 11.6 & & 148 & 20.5 & & 1009 & 26.8 & & 253 & 35.0 & \\
\hline \multicolumn{14}{|l|}{ Occupation } \\
\hline & clerk & 322 & 9.5 & 0.056 & 193 & 13.9 & 0.898 & 821 & 24.2 & $<0.001$ & 447 & 32.3 & 0.031 \\
\hline & sales & 427 & 10.0 & & 128 & 14.9 & & 1116 & 26.0 & & 273 & 31.7 & \\
\hline & research and development & 126 & 8.8 & & 109 & 13.3 & & 356 & 24.9 & & 280 & 34.1 & \\
\hline & engineer & 23 & 8.3 & & 9 & 10.5 & & 49 & 17.8 & & 15 & 17.4 & \\
\hline & production line and engineer & 123 & 7.9 & & 55 & 14.5 & & 285 & 18.2 & & 116 & 30.5 & \\
\hline & others & 16 & 7.0 & & 17 & 12.6 & & 45 & 19.7 & & 34 & 25.2 & \\
\hline \multirow[t]{4}{*}{ Marriage status } & Married & 845 & 9.6 & 0.069 & 243 & 13.7 & 0.403 & 2212 & 25.2 & $<0.001$ & 593 & 33.3 & 0.027 \\
\hline & Single & 167 & 8.0 & & 234 & 13.9 & & 403 & 19.3 & & 498 & 29.6 & \\
\hline & Divorce or bereavement & 22 & 8.4 & & 31 & 17.3 & & 49 & 18.8 & & 65 & 36.3 & \\
\hline & Missing & 3 & 7.9 & & 3 & 10.0 & & 8 & 21.1 & & 9 & 30.0 & \\
\hline \multirow[t]{5}{*}{ Education (graduate status) } & Junior high school or high school & 138 & 8.4 & 0.024 & 127 & 13.9 & 0.896 & 300 & 18.3 & $<0.001$ & 262 & 28.7 & 0.020 \\
\hline & $\begin{array}{l}\text { Junior college or technical school } \\
\text { or high professional school }\end{array}$ & 38 & 8.2 & & 93 & 13.4 & & 83 & 17.9 & & 206 & 29.6 & \\
\hline & College & 613 & 10.1 & & 196 & 14.5 & & 1568 & 25.7 & & 461 & 34.0 & \\
\hline & More than graduate school & 246 & 8.4 & & 92 & 13.5 & & 717 & 24.3 & & 229 & 33.7 & \\
\hline & Missing & 2 & 5.3 & & 3 & 11.5 & & 4 & 10.5 & & 7 & 26.9 & \\
\hline \multirow[t]{3}{*}{ Dental problems } & No & 897 & 8.7 & $<0.001$ & 457 & 13.4 & 0.001 & 2410 & 23.5 & $<0.001$ & 1075 & 31.5 & 0.113 \\
\hline & Yes & 118 & 19.2 & & 48 & 21.7 & & 219 & 35.6 & & 81 & 36.7 & \\
\hline & Missing & 22 & 7.4 & & 6 & 16.2 & & 43 & 14.4 & & 9 & 24.3 & \\
\hline \multirow[t]{5}{*}{ Overtime work hours } & None & 153 & 11.8 & 0.009 & 100 & 15.6 & 0.560 & 384 & 29.5 & $<0.001$ & 232 & 36.1 & 0.053 \\
\hline & $<20$ & 576 & 9.2 & & 315 & 13.7 & & 1479 & 23.6 & & 724 & 31.5 & \\
\hline & $20 \leq,<40$ & 240 & 8.7 & & 83 & 13.9 & & 634 & 22.9 & & 174 & 29.2 & \\
\hline & $40 \leq$ & 68 & 8.4 & & 12 & 11.4 & & 169 & 20.8 & & 31 & 29.5 & \\
\hline & Missing & 0 & 0 & & 1 & 4.5 & & 6 & 17.6 & & 4 & 18.2 & \\
\hline
\end{tabular}

Overtime work hours: mean overtime work hours per month in the last 6 months $P$-values calculated by chi-square tests

significant association between long working hours and preventive dental visits. As men get older, they may assume more managerial roles and think more about their responsibilities at work, which may result in putting off preventive dental visits. Among the respondents in this study, the proportion of male managers was $0.1 \%$ for those aged $\leq 29$ years and $3.3 \%$ for those in their 30 s, compared with $32.3 \%$ for those in their 40 s and $43.9 \%$ for those in their 50s. Previous research has shown that workers delay or skip preventive dental examinations because of lack of time or not wanting to burden their coworkers by delegating additional work [14]. Previous studies have also shown that workers who have more frequent dental visits are more likely to be absent from work [23]. In addition, many workers do not want to take time away from their jobs, and may therefore stop making preventive dental visits to avoid delaying or not completing work. However, few studies have investigated the reasons for failure to attend preventive dental visits, and more research is needed on this topic. This study also showed that there was no statistically significant association between long working hours and preventive dental visits among women of all ages. The proportion of female workers in managerial positions in this study was considerably lower than that of males $(0 \%$ for those $\leq 29$ years, $2.3 \%$ for those in their 30 s, $11.6 \%$ for those in 


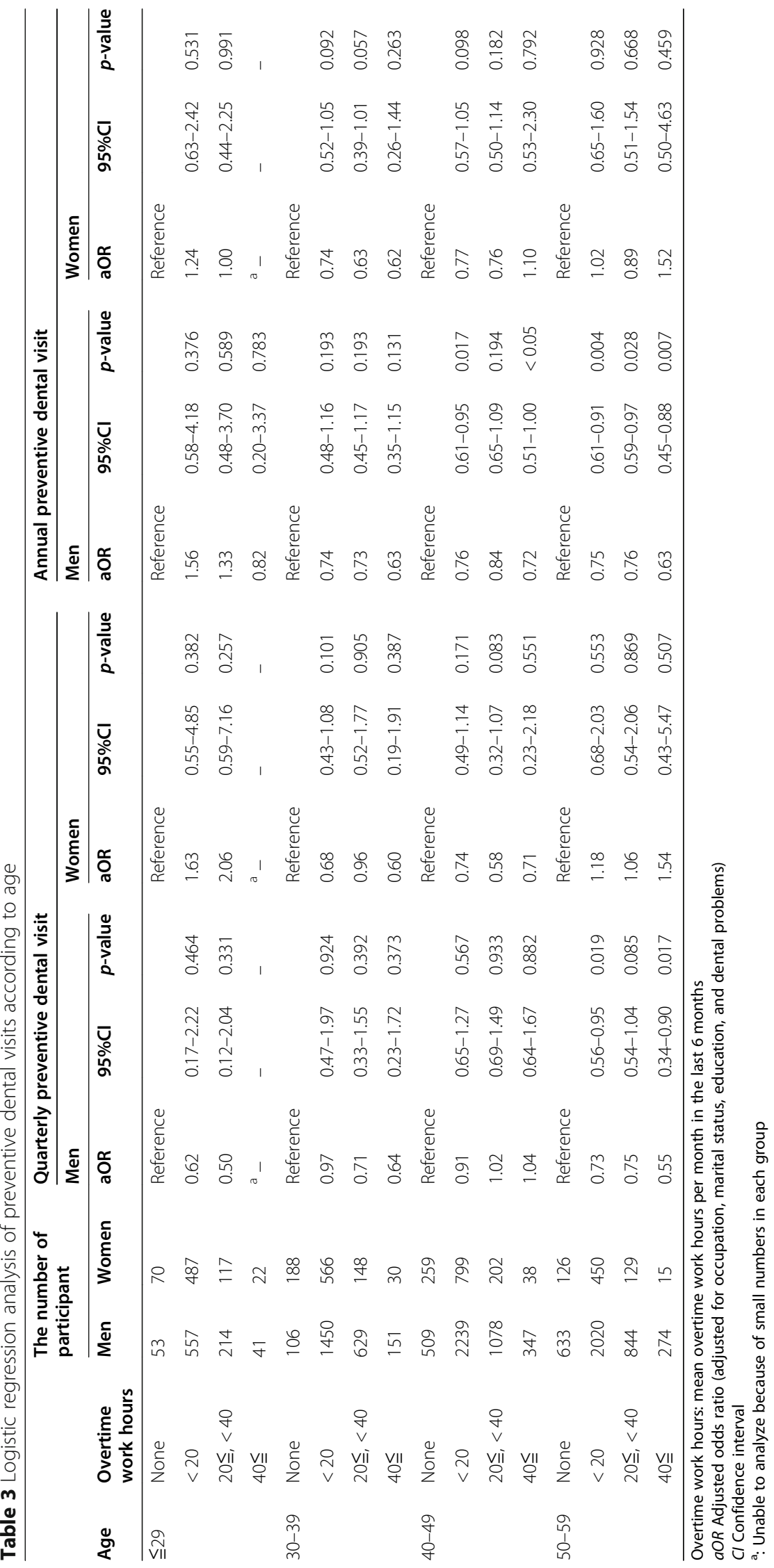




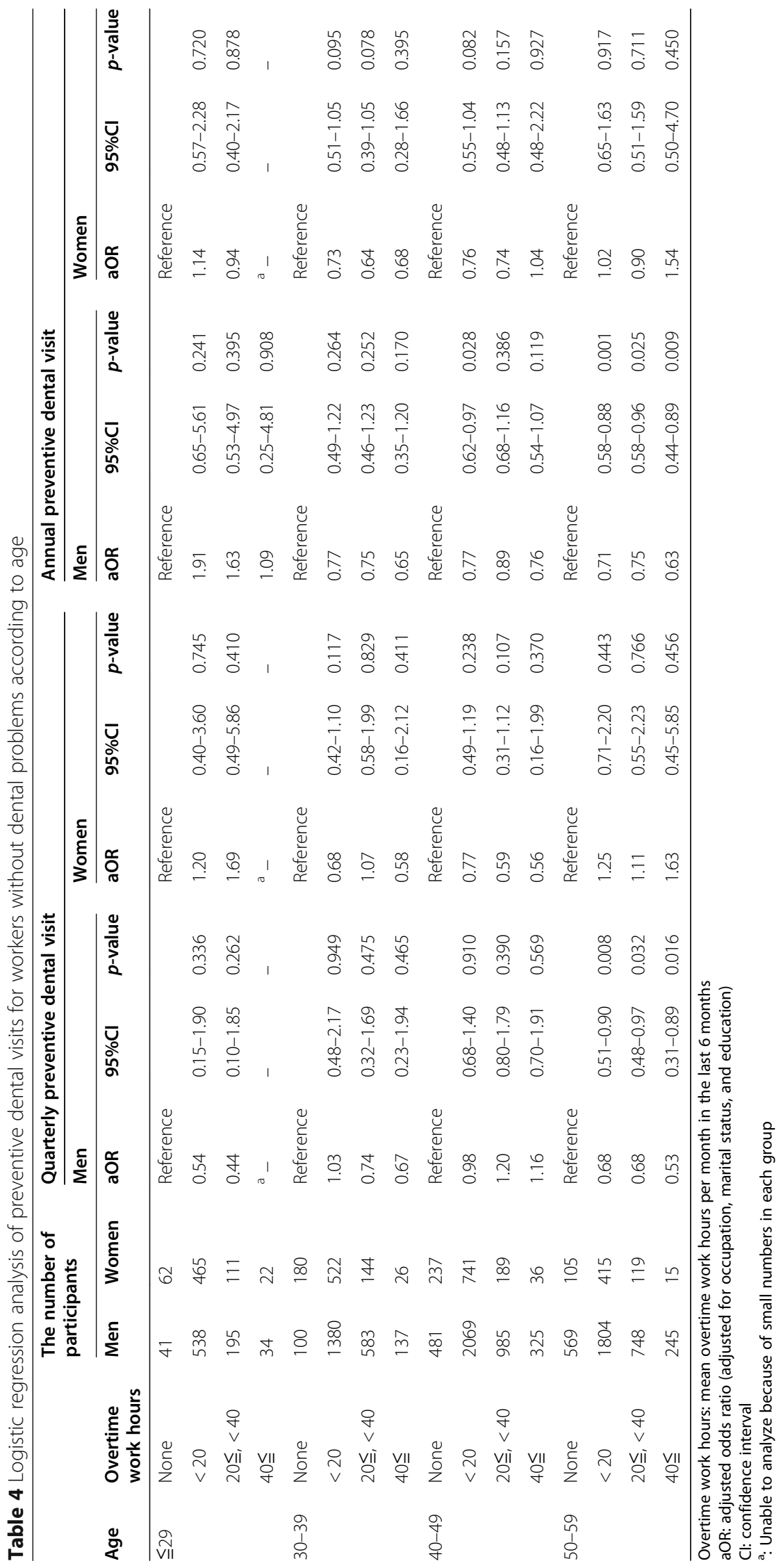


their $40 \mathrm{~s}$, and $10.4 \%$ for those in their $50 \mathrm{~s}$ ). However, the sample size of women in this study might not have been sufficient, and further studies with more women are needed.

The younger generation had a lower percentage of people who received preventive dental visits, although the proportion increased with age (Table 2). We also observed that women attended preventive dental visits more regularly than men. This was consistent with a previous study in the Japanese population, which reported that $6.5 \%$ of men and $9.0 \%$ of women attended 3monthly preventive dental visits, and $31.4 \%$ of men and $39.9 \%$ of women attended annual preventive dental visits [17]. Similar sex differences were observed in the present study (quarterly preventive dental visits: men 9.6\%, women 14\%; annual preventive dental visits: men $37.8 \%$, women $47.8 \%$ ).

The influence of overtime work hours on preventive dental visits in men was greater for annual visits, compared with quarterly visits. A previous study found oral health literacy was associated with the frequency of using regular dental care [24]. For workers attending quarterly dental visits, longer working hours did not appear to affect their dental clinic visits.

The results of this study suggested that even a relatively small amount of overtime work is likely to increase the risk for dental disease because it reduces the frequency of preventive dental visits. We believe that improving management of working hours and reducing the amount of overtime work are important factors for promoting preventive dental visits, which play a vital role in oral health. In addition to reducing overtime hours, it is important to consider other options, such as conducting dental examinations in workplace settings [25] or allowing workers to visit dental clinics during working hours, particularly younger workers and male workers aged over 40 years.

The main strengths of this study were the large sample size and the detailed analysis of Japanese people belonging to large companies. Our analyses were classified by the frequency of preventive dental visits and stratified by sex and age and adjusted for many covariates. This study also had some limitations. First, we were unable to examine causal relationships because this was a crosssectional study. It is difficult to assume a relationship whereby preventive dental visits affect overtime. Future longitudinal analyses using prospective cohort designs should be conducted. Second, our study used a selfadministered questionnaire to collect data on overtime and frequency of preventive dental visits, and recall bias might be present. Consideration should be given to obtaining objective data on overtime in further studies, such as obtaining company personnel data. Regarding preventive dental visits, it is difficult to distinguish between dental visits for treatment and preventive dental visits in objective data for receipts in Japan. Therefore, it is necessary to verify the validity of preventive dental visits by interviewing some respondents and asking them about their specific behavior and the purpose of their dental visits. The third limitation is the possibility of selection bias because the data were from employees of six large companies. The effects of overtime work may differ in our study population from those in the general population because background factors were evened out.

\section{Conclusion}

Our study revealed an association between overtime and preventive dental visits among male workers aged in their $40 \mathrm{~s}$ and $50 \mathrm{~s}$. In addition to reduction of overtime work, access to oral health measures in the workplace will help improve oral health in for people who work full-time.

\section{Supplementary Information}

The online version contains supplementary material available at https://doi. org/10.1186/s12889-020-10107-7.

Additional file 1. Self-administered questionnaire

Abbreviations

aOR: Adjusted odds ratio; Cl: Confidence interval

\section{Acknowledgements}

The authors thank the participants for their contribution to the study. We thank Edanz Group (https://en-author-services.edanzgroup.com/ac) for editing a draft of this manuscript.

\section{Authors' contributions}

All authors contributed to the study conception and design. TN, MN, and KM collected the data; $\mathrm{YH}$ and $\mathrm{TN}$ analyzed the data; and $\mathrm{YH}, \mathrm{TN}, \mathrm{AH}, \mathrm{RO}$, and $\mathrm{KM}$ led the writing. All authors have read and approved the manuscript, and ensure that this is the case.

\section{Funding}

The study was supported by the Collabo-health study group. The funding bodies played no role in the design of the study and collection, analysis, and interpretation of data and in writing the manuscript.

\section{Availability of data and materials}

The datasets generated during and/or analyzed during the present study are not publicly available because of the personal privacy of participants, but are available from the corresponding author on reasonable request.

\section{Ethics approval and consent to participate}

The research protocol was approved by the Ethics Committee of Medical Research, University of Occupational and Environmental Health, Japan ( $\mathrm{H}_{2} 6-$ 026). Written informed consent was obtained from all study participants, including consent to participate and publish the findings.

Consent for publication

Not applicable.

\section{Competing interests}

The authors declare that they have no competing interests.

\section{Author details}

${ }^{1}$ Department of Dentistry and Oral Surgery, University Hospital of

Occupational and Environmental Health, Kitakyushu, Japan. ${ }^{2}$ Department of 
Pathology, School of Medicine, University of Occupational and Environmental Health, Kitakyushu, Japan. ${ }^{3}$ Department of Occupational Health Practice and Management, Institute of Industrial Ecological Sciences, University of Occupational and Environmental Health, 1-1 Iseigaoka, Yahatanishi-ku, Kitakyushu 807-8555, Japan. ${ }^{4}$ Department of Occupational Medicine, School of Medicine, University of Occupational and Environmental Health, Kitakyushu, Japan.

Received: 25 June 2020 Accepted: 21 December 2020

Published online: 07 January 2021

\section{References}

1. Aida J, Ando Y, Akhter R, Aoyama H, Masui M, Morita M. Reasons for permanent tooth extractions in Japan. J Epidemiol. 2006;16(5):214-9.

2. Morita M, Kimura T, Kanegae M, Ishikawa A, Watanabe T. Reasons for extraction of permanent teeth in Japan. Community Dent Oral Epidemiol. 1994;22(5 Pt 1):303-6.

3. Yoshino K, Ito K, Kuroda M, Sugihara N. Prevalence of vertical root fracture as the reason for tooth extraction in dental clinics. Clin Oral Investig. 2015 19(6):1405-9.

4. Yoshino K, Suzuki S, Ishizuka Y, Takayanagi A, Sugihara N, Kamijyo H. Relationship between amount of overtime work and untreated decayed teeth in male financial workers in Japan. J Occup Health. 2017;59(3):280-5.

5. Morita I, Nakagaki H, Kato K, Murakami T, Tsuboi S, Hayashizaki J, et al. Relationship between survival rates and numbers of natural teeth in an elderly Japanese population. Gerodontology. 2006:23(4):214-8.

6. Saito M, Shimazaki Y, Nonoyama T, Tadokoro Y. Type of dental visit and number of remaining teeth in Japanese elders. J Oral Sci. 2018;60(4):611-7.

7. Bahekar AA, Singh S, Saha S, Molnar J, Arora R. The prevalence and incidence of coronary heart disease is significantly increased in periodontitis: a meta-analysis. Am Heart J. 2007;154(5):830-7.

8. Khader YS, Dauod AS, El-Qaderi SS, Alkafajei A, Batayha WQ. Periodontal status of diabetics compared with nondiabetics: a meta-analysis. J Diabetes Complications. 2006;20(1):59-68.

9. Lee W, Lim SS, Kim B, Won JU, Roh J, Yoon JH. Relationship between long working hours and periodontitis among the Korean workers. Sci Rep. 2017; 7(1):7967.

10. Caruso CC, Bushnell T, Eggerth D, Heitmann A, Kojola B, Newman K, et al. Long working hours, safety, and health: toward a National Research Agenda. Am J Ind Med. 2006;49(11):930-42.

11. Ganster DC, Rosen CC, Fisher GG. Long working hours and well-being: what we know, what we do not know, and what we need to know. J Bus Psychol. 2016;33(1):25-39.

12. Kivimaki M, Jokela M, Nyberg ST, Singh-Manoux A, Fransson El, Alfredsson L, et al. Long working hours and risk of coronary heart disease and stroke: a systematic review and meta-analysis of published and unpublished data for 603,838 individuals. Lancet. 2015;386(10005):1739-46.

13. Virtanen M, Stansfeld SA, Fuhrer R, Ferrie JE, Kivimaki M. Overtime work as a predictor of major depressive episode: a 5-year follow-up of the Whitehall II study. PLoS One. 2012;7(1):e30719.

14. Jun TW, Liebert CA, Esquivel M, Cox JA, Trockel M, Katznelson L. A protected time policy to improve dental health among resident physicians. J Am Dent Assoc. 2019;150(5):362-368.e6.

15. Needleman I, Nibali L, Di lorio A. Professional mechanical plaque removal for prevention of periodontal diseases in adults--systematic review update. J Clin Periodontol. 2015;42(Suppl 16):S12-35.

16. Lertpimonchai A, Rattanasiri S, Arj-Ong Vallibhakara S, Attia J, Thakkinstian A. The association between oral hygiene and periodontitis: a systematic review and meta-analysis. Int Dent J. 2017:67(6):332-43.

17. Ando Y, Ishida T, Fukai K, Oyama A. Factors related to regular visits to dental clinics. In: Health labour sciences research Grant survey: Ministry of health, labour and Welfare in Japan; 2011. https://www.niph.go.jp/soshiki/koku/ oralhealth/juq/jyukyu/docu22/docu22_14.pdf. Accessed 24 Jun. (In Japanese).

18. Schneider C, Zemp E, Zitzmann NU. Dental care behaviour in Switzerland. Swiss Dent J. 2019:129(6):466-78.

19. Soek H, Won JU, Lee TI, Kim YK, Lee W, Lee JH, et al. A dose-response relationship between long working hours and unmet need for access to hospital facilities. Scand J Work Environ Health. 2016;42(2):135-43.

20. Yao $X$, Dembe $A E$, Wickizer $T$, Lu B. Does time pressure create barriers for people to receive preventive health services? Prev Med. 2015;7(4):55-8.
21. Axelsson $\mathrm{P}$, Lindhe J. The significance of maintenance care in the treatment of periodontal disease. J Clin Periodontol. 1981;8(4):281-94.

22. Han DH, Khang YH, Jung-Choi K, Lim S. Association between shift work and periodontal health in a representative sample of an Asian population. Scand J Work Environ Health. 2013;39(6):559-67.

23. Lima RB, Buarque A. Oral health in the context of prevention of absenteeism and presenteeism in the workplace. Rev Bras Med Trab. 2019; 17(4):594-604.

24. Batista MJ, Lawrence HP, Sousa M. Oral health literacy and oral health outcomes in an adult population in Brazil. BMC Public Health. 2017;18(1):60.

25. Oshikohji T, Shimazaki Y, Shinagawa T, Fukui N, Akifusa S, Hirata Y, et al. Relationship between receiving a workplace oral health examination including oral health instruction and oral health status in the Japanese adult population. J Occup Health. 2011;53(3):222-9.

\section{Publisher's Note}

Springer Nature remains neutral with regard to jurisdictional claims in published maps and institutional affiliations.
Ready to submit your research? Choose BMC and benefit from:

- fast, convenient online submission

- thorough peer review by experienced researchers in your field

- rapid publication on acceptance

- support for research data, including large and complex data types

- gold Open Access which fosters wider collaboration and increased citations

- maximum visibility for your research: over $100 \mathrm{M}$ website views per year

At $\mathrm{BMC}$, research is always in progress.

Learn more biomedcentral.com/submissions 